\title{
Method for determination of stable carbon isotope ratio of methylnitrophenols in atmospheric particulate matter
}

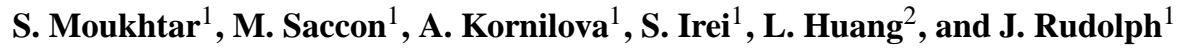 \\ ${ }^{1}$ Centre for Atmospheric Chemistry, Room 006 Steacie Science and Engineering Bldg., York University, 4700 Keele Street, \\ Toronto, Ontario, M3J 1P3 Canada \\ ${ }^{2}$ Atmospheric Science \& Technology Directorate, STB, Environment Canada, 4905 Dufferin Street, Toronto, \\ Ontario M3H 5T4, Canada
}

Received: 24 February 2011 - Published in Atmos. Meas. Tech. Discuss.: 25 May 2011

Revised: 26 September 2011 - Accepted: 21 October 2011 - Published: 16 November 2011

\begin{abstract}
A technique for the measurement of the stable isotope ratio of methylnitrophenols in atmospheric particulate matter is presented. Atmospheric samples from rural and suburban areas were collected for evaluation of the procedure. Particulate matter was collected on quartz fibre filters using dichotomous high volume air samplers. Methylnitrophenols were extracted from the filters using acetonitrile. The sample was then purified using a combination of high-performance liquid chromatography and solid phase extraction. The final solution was then divided into two aliquots. To one aliquot, a derivatising agent, Bis(trimethylsilyl)trifluoroacetamide, was added for Gas Chromatography-Mass Spectrometry analysis. The second half of the sample was stored in a refrigerator. For samples with concentrations exceeding $1 \mathrm{ng} \mathrm{\mu l}^{-1}$, the second half of the sample was used for measurement of stable carbon isotope ratios by Gas Chromatography-Isotope Ratio Mass Spectrometry.

The procedure described in this paper provides a method for the analysis of methylnitrophenols in atmospheric particulate matter at concentrations as low as $0.3 \mathrm{pg} \mathrm{m}^{-3}$ and for stable isotope ratios with an accuracy of better than $\pm 0.5 \%$ o for concentrations exceeding $100 \mathrm{pg} \mathrm{m}^{-3}$.

In all atmospheric particulate matter samples analysed, 2-methyl-4-nitrophenol was found to be the most abundant methylnitrophenol, with concentrations ranging from the low $\mathrm{pg} \mathrm{m}^{-3}$ range in rural areas to more than $200 \mathrm{pg} \mathrm{m}^{-3}$ in some samples from a suburban location.
\end{abstract}

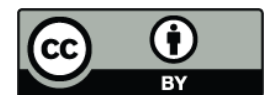

Correspondence to: J. Rudolph (rudolphj@yorku.ca)

\section{Introduction}

Particulate matter pollution has received much interest because of its significant impact on human health as well as climate change and local visibility (Thurston et al., 1994; Ramanathan et al., 2001; Anderson et al., 2003). Despite the well-known importance of particulate matter, the mechanisms and processes which determine the atmospheric levels of particulate matter are not well understood. One of the largest uncertainties stems from the limited understanding of the sources of atmospheric particulate organic matter (POM), which contributes typically in the range of $30-50 \%$ to atmospheric particulate matter (Blanchard et al., 2002). A significant fraction of atmospheric aerosol is secondary organic aerosol (SOA). The source of SOA is atmospheric degradation of volatile organic compounds (VOCs) such as benzene, toluene and other alkyl-benzenes, heavy alkenes and a variety of compounds emitted from vegetation, such as terpenes. There are numerous uncertainties in quantitative understanding of the rate and efficiency of atmospheric POM formation (Pandis et al., 1992; Turpin et al., 2000; Tsigaridis and Kanakidou, 2003).

During the last $15 \mathrm{yr}$, isotope ratio measurements of atmospheric VOC have been established as a tool to gain new insight into VOC chemistry (Rudolph et al., 1997; Tsunogai et al., 1999; Rudolph and Czuba, 2000; Thompson et al., 2002; Goldstein and Shaw, 2003; Harper et al., 2003; Redeker et al., 2007; Rudolph, 2007). More recently it also has been suggested that compound specific isotope ratio measurements can be used to study the formation of secondary organic pollutants from VOC degradation in the atmosphere (Irei et al., 2006, 2011; Irei, 2008, Fisseha et al., 2009; Li et al., 2010; Iannone et al., 2010).

Published by Copernicus Publications on behalf of the European Geosciences Union. 
One of the main obstacles for the use of isotope ratio measurements for studies of atmospheric SOA formation is the lack of tested and proven measurement methods. Using gas chromatography coupled online to isotope ratio mass spectrometry (GC-IRMS) allows compound specific isotope ratio measurements for atmospheric POM using methods similar to established procedures for quantitative analysis of POM. However, there are a number of considerations specific for isotope ratio analysis, which require substantial modification of existing methods. First of all, GC-IRMS measurements require orders of magnitude larger sample masses per measurement than GC coupled to conventional mass spectrometry or other state-of-the-art GC detectors. Furthermore, in the case of GC-IRMS measurements peak overlap can significantly bias isotope ratio evaluation since the only compound specific information in GC-IRMS is retention time. Finally, loss processes during sampling or sample processing can result in isotope fractionation. Internal standards are of limited value since isotope effects for reactions of internal standards are not necessarily identical to those of target compounds. Analysis of atmospheric POM typically requires complex sample processing, which often results in sample loss. However, physical loss processes, in contrast to chemical reactions, result in only small isotope fractionation (Huang et al., 1999). Consequently, sampling and processing of atmospheric POM for isotope ratio measurements primarily needs to avoid loss due to chemical reactions.

In this study, we focused on measurement of methylnitrophenol concentrations and stable isotope ratios in ambient particulate matter. Methylnitrophenols can be formed in the atmosphere from degradation of toluene in the gas phase. In studies examining the yield of phenols in POM resulting from degradation of VOC in smog chambers, the only identified precursor producing methylnitrophenols as a major product is toluene (Forstner et al., 1997; Jang and Kamens, 2001; Hamilton et al., 2005). This makes methylnitrophenols suitable candidates for the study of the relationship between secondary POM and VOC precursor in the atmosphere.

The method developed in this study was applied to analyze samples from rural and suburban areas. The samples were collected during the Border Air Quality Study (BAQS) campaign, which took place in June and July 2007 in Southern Ontario (Canada), close to the US border. In 2007 and 2008 samples were also collected in a suburban, mixed residential and industrial area (York University, Toronto, Canada).

\section{Materials and method}

\subsection{Sampling}

Particulate matter (diameter $<2.5 \mu \mathrm{m}$ ) was collected on $8 \times 10$ inch quartz fiber filters (Pallflex membrane filters - 2500QAT - PallGelman Sciences) using high volume air samplers (TE6070-BL PM2.5 Tisch Environmental, Inc.) equipped with
PM2.5 size selective inlets. Prior to sampling, new filters were baked under synthetic air at $1073 \mathrm{~K}$ for $48 \mathrm{~h}$ in a muffle furnace (Fisher Scientific Model 550-58, Napanee, Ontario, Canada) to remove organic contaminants. Each sample was collected for an average of three days. The average flow rate was $1.13 \mathrm{~m}^{3} \mathrm{~min}^{-1}$. Following sampling, filters were stored at $253 \mathrm{~K}$ in sealed glass jars. Particulate matter was collected during the BAQS campaign in June and July 2007 at Ridgetown and Harrow and in 2007 and 2008 at York University.

Ridgetown $\left(42^{\circ} 36^{\prime} \mathrm{N}, 81^{\circ} 53^{\prime} \mathrm{W}\right.$, elevation $\left.212 \mathrm{~m}\right)$ is a small town in Ontario (Canada) with a total population of about 3400 people. It is located about $100 \mathrm{~km}$ from the nearest major cities (London and Windsor, Ontario) and $120 \mathrm{~km}$ to $150 \mathrm{~km}$ from the nearest major urban and industrial centers (Detroit, Michigan and Cleveland, Ohio). Ridgetown is located about six kilometers south of a major freeway (McDonald-Cartier Freeway), and seven kilometers north of the shore of Lake Erie. The immediate surroundings consist of agricultural fields and local roads. The sampling site was set up on the Guelph University Ridgetown campus. Since there were no large point sources of major trace gases or industrial complexes within $100 \mathrm{~km}$ distance, this site meets the criteria for a rural site.

Harrow (Ontario, Canada, $42^{\circ} 02^{\prime} \mathrm{N}, 82^{\circ} 55^{\prime} \mathrm{W}$, elevation $191 \mathrm{~m}$ ) is a small town of around 3000 people. It is located approximately $40 \mathrm{~km}$ from two major cities (Windsor and Detroit) with a total population close to a million people. The sampling site was located in an open field surrounded by farm land and local roads.

Some samples were also collected in 2007 and 2008 on the roof of a parking garage at York University in Toronto, Canada. York University is located in a mixed industrialresidential area at the northern edge of Toronto (2.6 million inhabitants) about $15 \mathrm{~km}$ from the downtown business area and the shore of Lake Ontario. North of York University is the regional municipality of York $(\approx 1$ million inhabitants). A map indicating the sampling locations is shown in Fig. 1.

\subsection{Reagents and standards}

Standard and stock solutions of 2-methyl-4-nitrophenol (97\%, CAS: 99-53-6, Sigma-Aldrich), 4-methyl-2nitrophenol (98\%, CAS: 119-33-1, Sigma-Aldrich), 2-methyl-5-nitrophenol (97\%, CAS: 5428-54-6, SigmaAldrich), 2-methyl-3-nitrophenol (98\%, CAS: 5460-31-1, Sigma-Aldrich) and heptadecane (99\%, CAS: 629-78-7 Sigma-Aldrich) were prepared by diluting approximately $10 \mathrm{mg}$ of each pure methylnitrophenol in $100 \mathrm{ml}$ of acetonitrile (CHROMASOLV® Plus, for HPLC, $\geq 99.9 \%$ ) in $120 \mathrm{ml}$ brown glass vials. These stock solutions were prepared monthly. Solutions with lower concentrations (between 0.8 and $30 \mathrm{ng}^{-1} \mathrm{l}^{-1}$ ) were prepared by diluting the stock solutions with acetonitrile. These chemicals as well as the derivatisation agent 


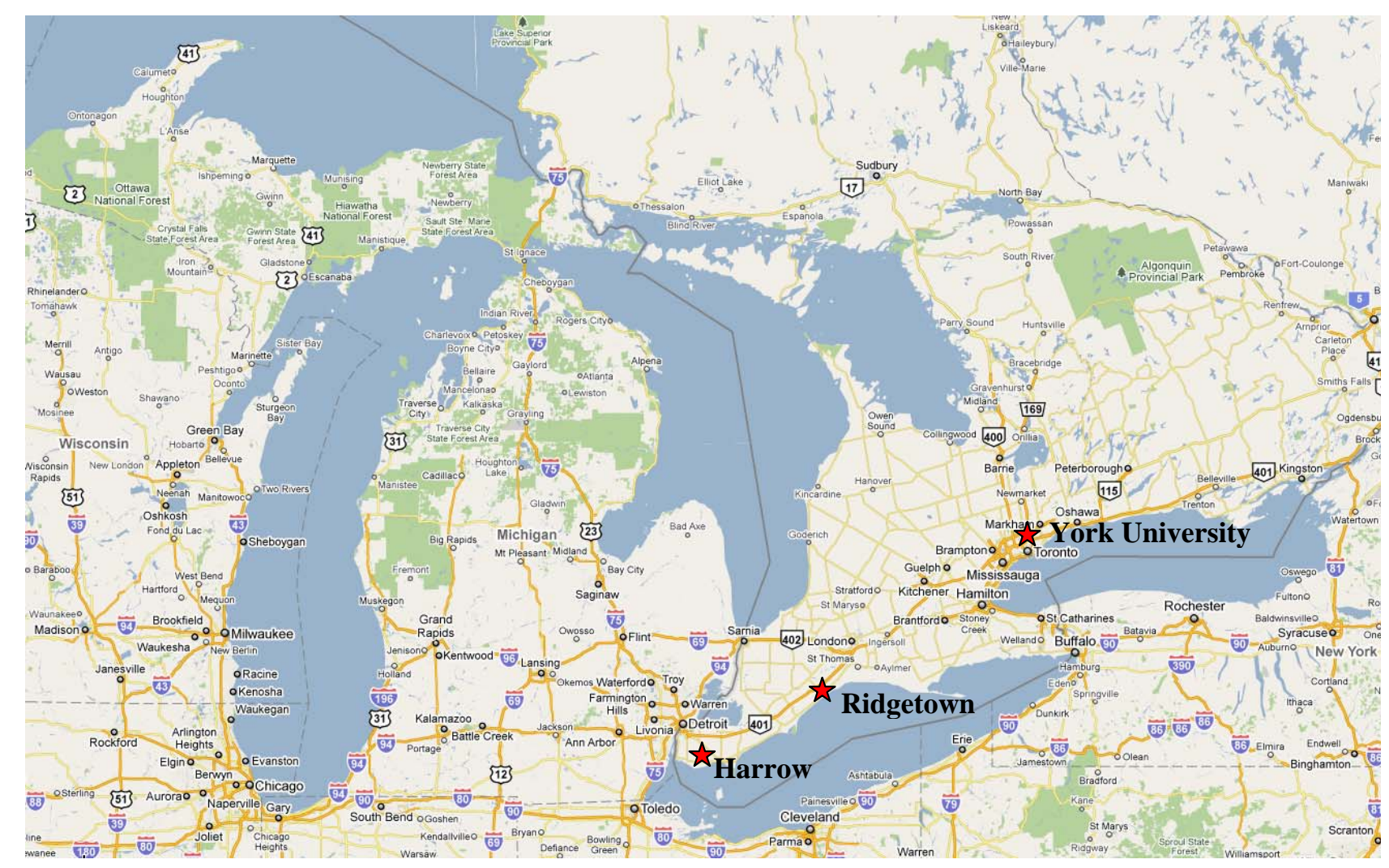

Fig. 1. Location of sampling sites.

N,O-bis(trimethylsilyl)trifluoroacetamide (BSTFA, ethanimidic acid, 2,2,2-trifluoro-N-(trimethylsilyl)-, trimethylsilyl ester, CAS: 25561-30-2 purchased from Regis technology) were of the highest purity commercially available and were used without further purification.

\subsection{Extraction procedure}

The extraction method was based on one devised by Rudolph and Stupak (2002), but in order to be applicable to stable isotope ratio analysis of methynitrophenols at trace levels several changes were made. Following sample collection, two internal standards were spiked on the filter. The filter was then cut into several pieces and placed in a glass jar. The filter pieces were fully immersed in acetonitrile (approximately $20 \mathrm{ml}$ ) and the jar was placed in an ultrasonic bath (Bransonic Ultrasonic Cleaner, Model SS10R-DTH) for $15 \mathrm{~min}$. The liquid phase was removed using a Pasteur pipette and loaded into a syringe through a $45 \mu \mathrm{m}$-pore-diameter PTFE Chromspec filter. This extraction was repeated three times.

The combined liquid phases of approximately $50 \mathrm{ml}$ were evaporated to a volume of a few milliliters under vacuum at a temperature of $315 \mathrm{~K}$ using a rotary evaporator. The volume of the solution was then further reduced under a stream of pure nitrogen and mechanical stirring to 200-300 $\mu$ l. The concentrated solution was injected into a HPLC (Hewlett
Packard 1050) and separated on a Supelcosil LC-18 column ( $5 \mu \mathrm{m}$ particles size, L $25 \mathrm{~cm}$, I.D. $4.6 \mathrm{~mm}$ ). The variable wavelength detector was set to $320 \mathrm{~nm}$ to monitor the elution of methylnitrophenols. Solvent flow rate was $1 \mathrm{ml} \mathrm{min}^{-1}$. A linear solvent gradient was used, starting with $100 \%$ water (deionized milli Q-water, $18 \Omega$ ) and ending after $30 \mathrm{~min}$ with $100 \%$ of acetonitrile.

The eluent fraction containing the target compounds and internal standards was collected during a specified time window into a glass flask. The volume of the collected solution (several millilitres containing approximately equal amounts of acetonitrile and water) was reduced by half using a rotator evaporator. During volume reduction the temperature of the solution was kept between $278 \mathrm{~K}$ and $283 \mathrm{~K}$. The remaining solution was acidified with phosphoric acid to a final $\mathrm{pH}$ of around 2. This solution was then subjected to solid phase extraction (SPE) using Waters Oasis HLB cartridges. Prior to their use, the SPE cartridges were conditioned by rinsing with $1 \mathrm{ml}$ of methanol followed by $1 \mathrm{ml}$ of milli-Q water. The acidified solution was then passed through the cartridge. A few millilitres of milli-Q water were dispensed into the flask, acidified with $\mathrm{H}_{3} \mathrm{PO}_{4}$ to a $\mathrm{pH}$ of 2 and also passed through the cartridge. For recovery of the methylnitrophenols, the SPE cartridge was extracted with approximately $10 \mathrm{ml}$ of acetonitrile. The eluent was collected in a 
Table 1. Target compounds, internal standards, internal standards recovery control, HPLC collection windows and GC column used for methylnitrophenol analysis.

\begin{tabular}{ll}
\hline Target compounds & $\begin{array}{l}\text { 4-methyl-2-nitrophenol } \\
\text { 2-methyl-4-nitrophenol }\end{array}$ \\
\hline Internal standards & $\begin{array}{l}\text { 2-methyl-3-nitrophenol } \\
\text { 2-methyl-5-nitrophenol }\end{array}$ \\
\hline Internal standards recovery control & Heptadecane \\
\hline HPLC collection window & From 12 min to $15.5 \mathrm{~min}$ \\
\hline GC column & $\begin{array}{l}\text { DB-5MS }(60 \mathrm{~m} \times 0.25 \mathrm{~mm} \\
\text { i.d. } \times 1 \mu \mathrm{m} \text { film thickness })\end{array}$ \\
\hline
\end{tabular}

flask and evaporated using a rotary evaporator until the volume of the solution was approximately $1 \mathrm{ml}$. The solution was then transferred into a conic vial. The flask was rinsed several times with acetonitrile which was then added to the conic vial before the volume was reduced under a flow of nitrogen and mechanical stirring to approximately $100 \mu \mathrm{l}$.

Then $20 \mu \mathrm{l}$ of an internal standard for recovery control was added to the final solution. Half of the solution was saved in a glass vial and stored at $253 \mathrm{~K}$ for later stable isotope ratio analysis. The other half of the solution was derivatized by adding $10 \mu \mathrm{l}$ of BSTFA. $1 \mu \mathrm{l}$ of this derivatized solution was injected splitless into a GC-MS (HP 5890 Series II GC with HP 5972 Series MS detector). Chromatographic column was a DB-5MS column $(60 \mathrm{~m} \times 0.25 \mathrm{~mm}$ i.d. $\times 1 \mu \mathrm{m}$ film thickness).

The temperature of the GC column was initially held at $373 \mathrm{~K}$ for $10 \mathrm{~min}$ then programmed to $453 \mathrm{~K}$ at $10 \mathrm{~K} \mathrm{~min}^{-1}$, to $493 \mathrm{~K}$ at $1 \mathrm{~K} \mathrm{~min}^{-1}$ and to $553 \mathrm{~K}$ at $4 \mathrm{~K} \mathrm{~min}^{-1}$. The final temperature, $553 \mathrm{~K}$, was held for $6 \mathrm{~min}$. Helium was used as the carrier gas at a flow rate of $2 \mathrm{ml} \mathrm{min}^{-1}$.

Typically, each sample was analyzed three times using selective ion monitoring (SIM), using three characteristic $\mathrm{m} / \mathrm{z}$ values as well as once in scanning mode. Methylnitrophenol concentrations were determined from the SIM chromatograms.

Concentrated extracts with methylnitrophenol concentrations exceeding $1 \mathrm{ng} \mathrm{\mu l}^{-1}$ and total ion current chromatograms showing no overlapping for the peaks of the target compounds were analyzed for stable carbon isotope ratios. In this case, the stored solution was reduced to a few microliters under a flow of nitrogen, derivatized using BSTFA and analyzed with an online GC-IRMS instrument (Finnigan, MAT 252) at Environment Canada (Toronto, Canada). The GC (Varian 3600) was equipped with a DB-5MS column $(60 \mathrm{~m} \times 0.25 \mathrm{~mm}$ i.d. $\times 1 \mu \mathrm{m}$ film thickness $)$. Temperature program and flow rate were similar to those used for GCMS measurements. The column was connected to a combustion interface that converts the organic components in the

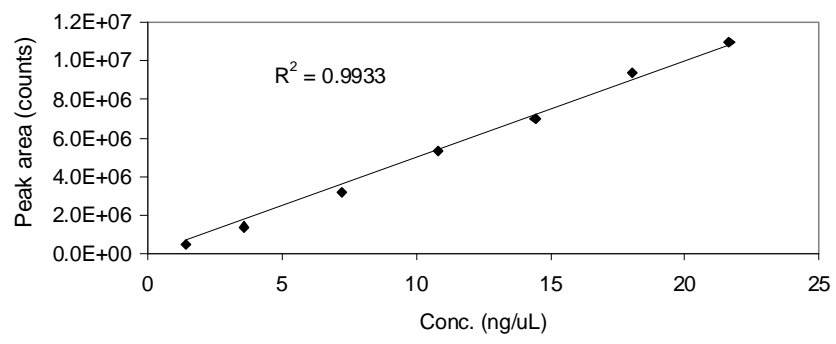

Fig. 2. Example of GC-MS calibration for 2-methy-4-nitrophenol.

column effluent to carbon dioxide and water. The design of the interface was very similar to that described by Matthew and Hayes (1978) and was modified (Irei, 2008) for methylnitrophenol analysis. After the combustion interface, the carrier gas passed through a Nafion permeation dryer. About $0.5 \mathrm{ml} \mathrm{min}^{-1}$ of the carrier gas was transferred via an open split and a fused silica restriction capillary to the ion source of the isotope ratio mass spectrometer. For calibration of the isotope ratio measurements, a reference gas containing carbon dioxide with a ${ }^{13} \mathrm{C} /{ }^{12} \mathrm{C}$ ratio traceable to the internationally used Vienna-Pee Dee Belemnite (V-PDB) reference point was added via an open split for $20 \mathrm{~s}$ at different times during the analysis.

Through testing different target compounds, internal standards, internal standards for recovery controls, varying HPLC collection windows as well as changing the GC column type, a procedure suitable for isotope ratio analysis was developed. The specifics of the procedures are summarized in Table 1. 2-Methyl-4-nitrophenol and 4-methyl-2nitrophenol have been chosen as target compounds as they were the most abundant nitrophenols in our atmospheric particulate matter samples.

2-Methyl-5-nitrophenol and 2-methyl-3-nitrophenol, were selected as internal standards for their structural and chemical similarities with the target compounds. Analysis of atmospheric particulate matter samples collected at York University without adding these internal standards showed no detectable signals for these two compounds.

\section{Calibration and method validation}

\subsection{GC-MS system}

Calibrations of the GC-MS system were performed at eight concentration levels ranging from 0.8 to $30 \mathrm{ng}_{\mu l^{-1}}$ with three repeat measurements for each level (Fig. 2). The average relative standard deviation of repeat measurements was less than $5 \%$.

The extraction procedure was applied to three blank quartz filters and to one field blank filter. The field blank filter was transported to the BAQS field site and handled in the same way as the other filters, but no particulate matter were 
collected on this filter. Target compounds and internal standards were never detected in these blank filters. Quantitative detection limits for methylnitrophenols were calculated using baseline noise from chromatograms of blank filter extracts. Using SIM mode the average detection limit was $5 \mathrm{pg}^{-1} \mathrm{l}^{-1}$. For the three days of sampling with a flow rate of $1.13 \mathrm{~m}^{3} \mathrm{~min}^{-1}$, a volume of $100 \mu \mathrm{l}$ for the processed filter extract, and a recovery of $40 \%$ for the extraction procedure (see below) this corresponds to detection limits of approximately $0.3 \mathrm{pg} \mathrm{m}^{-3}$ in air.

Recovery of the method was tested by spiking $1 \mu \mathrm{g}$ or $4 \mu \mathrm{g}$ of each target compound and internal standard on a quartz filter before extraction. Two different types of tests were performed; in one set methylnitrophenols were spiked on clean, pre-baked filters and in another set on filters on which PM2.5 had been collected for 3 days.

The recovery for each internal standard was consistently between $35 \%$ and $50 \%$ independent of the mass spiked on the filter (Table 2). Using the average recovery for the two internal standards, the target compound masses were calculated and compared to the spiked mass. As can be seen from Table 2, with very few exceptions, the recovery relative to the internal standards was quantitative within $10 \%$. For 4-methyl-2-nitrophenol, the average internal standard corrected recovery was $92 \pm 9 \%$. Although this average value is only slightly below $100 \%$ and is within the estimated range of uncertainty for recovery, this was taken into account when calculating its mass for ambient samples. No correction was made for 4-methyl-2-nitrophenol since any correction would have been well below the reproducibility of the measurements.

In order to determine the recovery for individual steps of the procedure, different methylnitrophenols were added at several stages of the sample preparation procedure. First, 2-methyl-3-nitrophenol was spiked on the clean filter before extraction. Then 3-methyl-2-nitrophenol was added to the solution before HPLC separation and 4-methyl-2nitrophenol was added to the solution collected from the HPLC. Afterwards, 2-Methyl-5-nitrophenol was spiked to the solution just before the solid phase extraction and 2methyl-4-nitrophenol was spiked before the final volume reduction step. The results of this test are presented in Table 3.

\subsection{GC-IRMS measurements}

Stable carbon isotope ratios are generally measured and calculated in the form of relative differences between sample and reference standard $\left(\delta^{13} \mathrm{C}\right)$. Changes in isotopic composition are usually small; they typically are given in permil (1).

$\delta^{13} \mathrm{C}(\% o)=$

$\left(\mathrm{C}_{13} / \mathrm{C}_{12}-{ }^{\mathrm{ref}} \mathrm{C}_{13} /{ }^{\mathrm{ref}} \mathrm{C}_{12}\right) /\left({ }^{\mathrm{ref}} \mathrm{C}_{13} /{ }^{\mathrm{ref}} \mathrm{C}_{12}\right) \times 1000 \%$

Here, $\mathrm{C}_{13}$ and $\mathrm{C}_{12}$ denote the abundance of different isotopes in the studied compound, and ${ }^{\text {ref }} \mathrm{C}$ is the reference standard. The isotope ratios reported here are relative to V-PDB.
To determine the carbon stable isotope ratio of methylnitrophenols by GC-IRMS, GC-traces for masses $44\left({ }^{12} \mathrm{C}^{16} \mathrm{O}_{2}\right), \quad 45\left({ }^{13} \mathrm{C}^{16} \mathrm{O}_{2}\right.$ and $\left.{ }^{12} \mathrm{C}^{17} \mathrm{O}^{16} \mathrm{O}\right)$ and 46 $\left({ }^{12} \mathrm{C}^{18} \mathrm{O}^{16} \mathrm{O}\right)$ were monitored and stored for subsequent evaluation of the chromatograms. The areas of the chromatographic peaks for masses 44,45 and 46 were determined manually. The ${ }^{13} \mathrm{C} /{ }^{12} \mathrm{C}$ ratio was calculated from the mass $45 / 44$ ratio after applying a small correction for the ${ }^{17} \mathrm{O}$ contribution to mass 45 following the procedure suggested by Craig (1957).

The correction procedure has been slightly modified to avoid biased correction due to the contribution of $\mathrm{NO}_{2}$ to $\mathrm{m} / \mathrm{z} 46$ using a method described in detail by Irei (2008). An additional correction was applied to correct for the change in stable carbon isotope ratio resulting from derivatisation. Since the reaction between BSTFA and methylnitrophenols occurs without breaking or forming a carbon bond, carbon isotope fractionation due to the reaction will be limited to secondary isotope effects and therefore negligible. However, the addition of three carbon atoms to the methylnitrophenols induces a change in the isotopic composition which has to be corrected using mass balance.

$\delta^{13} \mathrm{C}_{\text {free }}=\frac{\# \mathrm{C}_{\text {deriv }}}{\# \mathrm{C}_{\text {free }}} \times \delta^{13} \mathrm{C}_{\text {deriv }}-\frac{\# \mathrm{C}_{\mathrm{TMS}}}{\# \mathrm{C}_{\text {free }}} \times \delta^{13} \mathrm{C}_{\mathrm{TMS}}$

$\# \mathrm{C}_{\text {deriv }}, \# \mathrm{C}_{\text {free }}$ and $\# \mathrm{C}_{\mathrm{TMS}}$ are the number of carbon atoms in the derivative, free methylnitrophenol and the trimethylsillyl (TMS) group, respectively. $\delta^{13} \mathrm{C}_{\text {deriv }}$ and $\delta^{13} \mathrm{C}_{\mathrm{TMS}}$ are the stable carbon isotope ratio of derivatized methylnitrophenol and the TMS group. $\delta^{13} \mathrm{C}_{\text {free }}$, represents the stable carbon isotope ratio of underivatized methylnitrophenol.

In order to determine the carbon isotope ratio of the TMS group, solutions with high concentrations of methylnitrophenols (between 15 and $35 \mathrm{ngl}^{-1}$ ) were prepared from pure methylnitrophenols. The stable carbon isotope ratios of bulk methylnitrophenols were determined by off-line combustion of pure substances and subsequent dual-inlet analysis of the carbon isotope ratio of the formed $\mathrm{CO}_{2}$. In total twelve standard solutions were analysed by GC-IRMS. For each measurement $\delta^{13} \mathrm{C}_{\mathrm{TMS}}$ was calculated using mass balance (Eq. 2) and $\delta^{13} \mathrm{C}_{\text {free }}$ values from off-line measurements. There was no significant difference between $\delta^{13} \mathrm{C}_{\mathrm{TMS}}$ values derived from measurements of different methylnitrophenols and the overall average of $-45.31 \pm 0.07 \%$ (standard deviation of $0.51 \%$ ) was used for the correction.

To check GC-IRMS stability and to verify absence of isotope fractionation during GC-IRMS analysis bulk nitrophenols were analysed for their carbon isotope ratios using standard offline oxidation and dual-inlet isotoperatio anal-

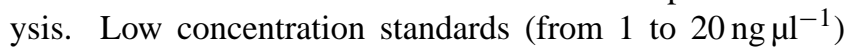
were prepared from the pure methylnitrophenols and measured by GC-IRMS before and after sample analysis. The average relative standard deviation of repeat isotopic ratios measurements was less than $0.2 \%$. The observed difference between GC-IRMS measurements and $\delta^{13} \mathrm{C}$ values 
Table 2. Recovery for internal standards and recovery relative to internal standards for target compounds spiked on clean filters and on filters containing atmospheric particulate matter.

\begin{tabular}{|c|c|c|c|c|c|c|c|}
\hline & Clean filter & Clean filter & Clean filter & Ambient filter ${ }^{\mathrm{a}}$ & Ambient filter ${ }^{b}$ & \multirow{5}{*}{$\begin{array}{l}\text { Average } \\
\text { Recovery } \\
\text { ratio }(\%)\end{array}$} & \multirow{5}{*}{$\begin{array}{l}\text { Stdev } \\
(\%)\end{array}$} \\
\hline Mass spiked ( $\mu \mathrm{g})$ & 4 & 4 & 1 & 4 & 4 & & \\
\hline \multicolumn{6}{|c|}{ Internal standards recovery $(\%)$} & & \\
\hline 2-methyl-3-nitrophenol & $43 \pm 4$ & $40 \pm 4$ & $39 \pm 3$ & $37 \pm 3$ & $42 \pm 4$ & & \\
\hline 2-methyl-5-nitrophenol & $45 v \pm 4$ & $39 \pm 5$ & $41 \pm 3$ & $44 \pm 3$ & $48 \pm 5$ & & \\
\hline \multicolumn{8}{|c|}{ Recovery relative to internal standards (\%) } \\
\hline 4-methyl-2-nitrophenol & $77 \pm 11$ & $91 \pm 10$ & $100 \pm 9$ & $86 \pm 9$ & $93 \pm 9$ & 92 & 9 \\
\hline 2-methyl-4-nitrophenol & $100 \pm 8$ & $101 \pm 8$ & $108 \pm 6$ & $125 \pm 7$ & $87 \pm 7$ & 97 & 9 \\
\hline
\end{tabular}

a Samples collected at York University from 03/08/07 to 06/08/07. ${ }^{\text {b }}$ Samples collected at York University from 25/09 to 28/09/07.

Table 3. Recoveries of methylnitrophenols spiked at different stages of the sample preparation procedure.

\begin{tabular}{lrr}
\hline Compound spiked & $\begin{array}{r}\text { Extraction steps at which } \\
\text { standard was added }\end{array}$ & $\begin{array}{r}\text { Recovery for } \\
\text { individual step (\%) }\end{array}$ \\
\hline 2-methyl-3-nitrophenol & Filter extraction & 78 \\
3-methyl-2-nitrophenol & HPLC separation & 78 \\
4-methyl-2-nitrophenol & Volume reduction of & 86 \\
& HPLC eluent & \\
2-methyl-5-nitrophenol & SPE & 87 \\
2-methyl-4-nitrophenol & Final volume reduction & 100 \\
Combined recovery & All steps combined & 46 \\
\hline
\end{tabular}

from off-line analysis of pure methylnitrophenols was mostly below $0.5 \%$ o (Fig. 3).

To evaluate possible isotopic fractionation that may occur during extraction, one microgram of each target compound was spiked on two blank filters. These filters were then extracted following the standard procedure and the carbon isotopic composition of the extracted methylnitrophenols was measured and compared with offline analysis (Table 4). The results of the online measurements agreed with the offline values within better than $0.5 \%$.

\section{Results of ambient measurements}

\subsection{Concentration of methylnitrophenols in atmospheric particulate matter}

The results of the analysis of filters collected during the BAQS campaign are summarized in Table 5 and the results for filters collected at York University in Table 6. For all samples from BAQS, methylnitrophenol concentrations were very low and could only be determined reliably using selective ion chromatograms. The average recovery calculated for both internal standards in these extractions was $46 \pm 5 \%$.
The average concentrations were $11.5 \pm 2.8 \mathrm{pg} \mathrm{m}^{-3}$ and $4.7 \pm 1.4 \mathrm{pg} \mathrm{m}^{-3}$ for 2-methyl-4-nitrophenol and 4-methyl2-nitrophenol, respectively, in particulate matter collected at Ridgetown. In particulate matter collected at Harrow, the concentrations were on average very similar, $14.8 \pm 3.7 \mathrm{pg} \mathrm{m}^{-3}$ and $6.0 \pm 1.8 \mathrm{pg} \mathrm{m}^{-3}$ for 2-methyl-4nitrophenol and 4-methyl-2-nitrophenol, respectively. The concentrations of 2-methyl-4-nitrophenol at York University were on average $144 \pm 60 \mathrm{pg} \mathrm{m}^{-3}$, approximately an order of magnitude higher than at Harrow and Ridgetown. This is consistent with the expectation of higher levels of pollutants at York University due to its location at the edge of a city of several million inhabitants.

\subsection{Stable isotope ratio measurements}

For five of the samples collected at York University, stable carbon isotope ratio measurement for the most abundant target compound, 2-methyl-4-nitrophenol, was possible (Table 7). For these samples, no overlapping between 2-methyl-4-nitrophenol and other compounds occurred and the extract concentration was sufficient for accurate GC-IRMS measurements.

Two measurements were performed for each sample. Stable carbon isotope ratios of these repeat measurements agreed within $0.1 \%$. The isotope ratios of 2-methyl-4nitrophenol ranged from $-31.6 \%$ to $-32.9 \%$. Based on the tests performed, the accuracy of the measurements is estimated to be $0.5 \%$.

\section{Discussion}

Depending on sampling duration, particulate matter from around $1000 \mathrm{~m}^{3}$ to $5000 \mathrm{~m}^{3}$ of air is collected on the quartz fibre filters. The concentrations of particulate matter with a diameter of less than $2.5 \mu \mathrm{m}$ generally ranges from several $\mu \mathrm{g} \mathrm{m}^{-3}$ in remote rural areas to $100 \mu \mathrm{g} \mathrm{m}^{-3}$ or more for 


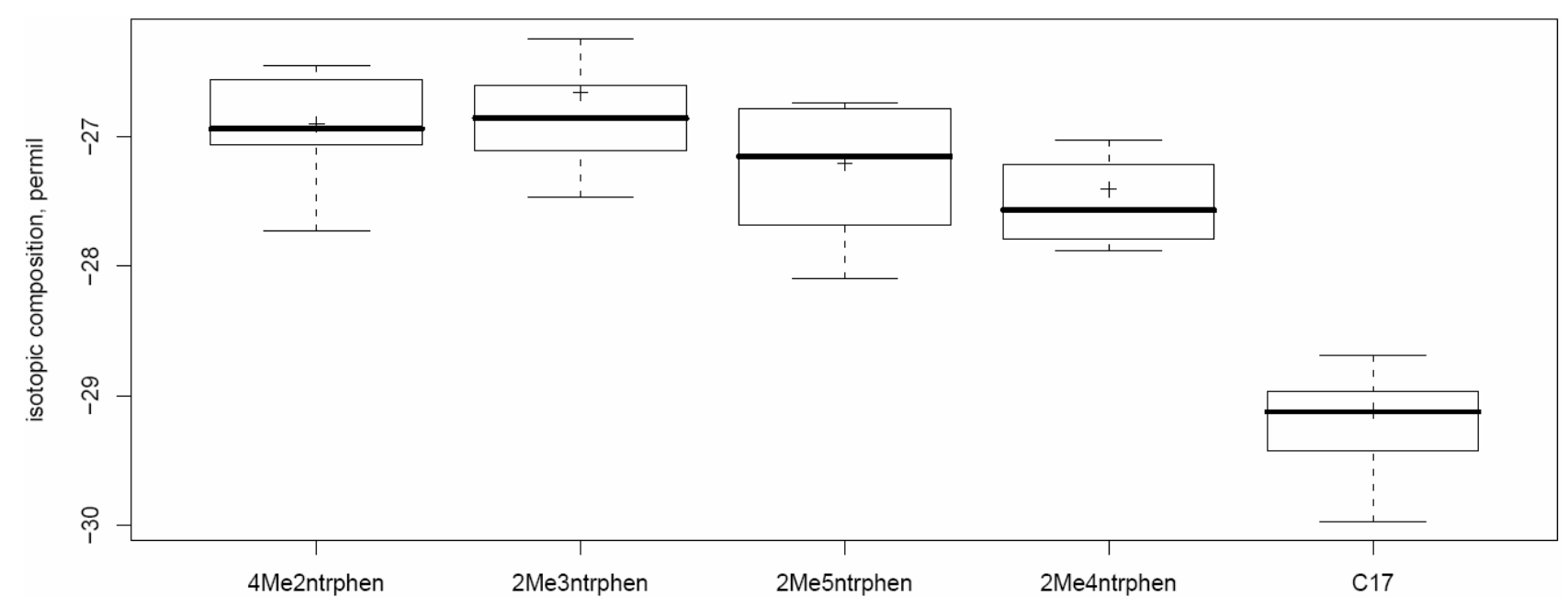

Fig. 3. Comparison of online and offline isotope ratio measurements for methylnitrophenols. (+) represents the offline value. The box plot represents GC-IRMS measurements of solutions containing between 1 to $20 \mathrm{ng}^{-1}$. The heavy lines give the median values, the boxes indicate the 25 and 75 percentile range and the upper and lower ends of the vertical bars the extreme values of the measurements.

Table 4. Results of GC-IRMS analysis of $1 \mu \mathrm{g}$ of each compound spiked on blank filters. For comparison the results from off-line analysis of bulk material are also presented.

\begin{tabular}{|c|c|c|c|c|c|c|}
\hline & $\begin{array}{c}\text { Mass } \\
\text { spiked }\end{array}$ & \multicolumn{3}{|c|}{ Test 1} & \multicolumn{2}{|c|}{ Test 2} \\
\hline Compounds & $\mu \mathrm{g}$ & $\begin{array}{r}\text { Offline } \\
\delta^{13} \mathrm{C} \\
(\% o)\end{array}$ & $\begin{array}{r}\text { Online } \\
\delta^{13} \mathrm{C}^{*} \\
(\% o)\end{array}$ & $\begin{array}{r}\text { Offset } \\
(\% o)\end{array}$ & $\begin{array}{r}\text { Online } \\
\delta^{13} \mathrm{C}^{*} \\
(\% \circ)\end{array}$ & $\begin{array}{r}\text { Offset } \\
(\% o)\end{array}$ \\
\hline $\begin{array}{l}\text { Internal Standards } \\
\text { 2-me-3-nitrophenol } \\
\text { 2-me-5-nitrophenol }\end{array}$ & $\begin{array}{l}1 \\
1\end{array}$ & $\begin{array}{l}-26.66 \\
-27.20\end{array}$ & $\begin{array}{l}-26.95 \\
-27.32\end{array}$ & $\begin{array}{l}-0.29 \\
-0.12\end{array}$ & $\begin{array}{l}-27.07 \\
-27.00\end{array}$ & $\begin{array}{r}-0.41 \\
0.20\end{array}$ \\
\hline $\begin{array}{l}\text { Target Compounds } \\
\text { 2-me-4-nitrophenol } \\
\text { 4-me-2-nitrophenol }\end{array}$ & $\begin{array}{l}1 \\
1\end{array}$ & $\begin{array}{l}-27.41 \\
-26.90\end{array}$ & $\begin{array}{l}-27.80 \\
-26.66\end{array}$ & $\begin{array}{r}-0.39 \\
0.24\end{array}$ & $\begin{array}{l}-27.63 \\
-26.65\end{array}$ & $\begin{array}{r}-0.23 \\
0.25\end{array}$ \\
\hline $\begin{array}{l}\text { Internal Standards } \\
\text { Recovery Control } \\
\text { C17 }\end{array}$ & 4 & -28.06 & -28.57 & -0.51 & -28.39 & -0.33 \\
\hline
\end{tabular}

*Average of three repeat measurements.

heavily polluted urban and industrialized locations. Consequently, the mass of particulate matter accumulated on the filter is in the range from several $10 \mathrm{mg}$ to some $100 \mathrm{mg}$. The mass of methylnitrophenols in the samples is in the range of $10 \mathrm{ng}$ to $500 \mathrm{ng}$. Based on the detection limit of $5 \mathrm{pg}^{-1}$, analyses of methylnitrophenols in extract volumes of a few millilitres is in principle possible. However, such a sample will also contain a wide range of different organic and inorganic substances at a total concentration in the range of some ten $\mu \mathrm{g}^{-1}$ or more. Such a large excess of a complex and variable matrix makes reliable detection of trace components without further sample clean-up extremely difficult, if not impossible. While in the case of concentration measurement, conventional GC-MS detection to some extent may help to reduce interference problems. This option does not exist for GC-IRMS where all peak overlaps will result in biased isotope ratios. The use of HPLC as sample clean-up procedure allows to greatly reduce overlap probability. Sample clean-up by HPLC allows easy tuning for different sets of target compounds. The risk of interfering overlap in the 
Table 5. Mass (ng) of 2-methyl-4-nitrophenol and 4-methyl-2-nitrophenol in $1 \mu$ of the final solution from extraction of filters collected at Harrow and Ridgetown during BAQS and the corresponding concentrations in the atmosphere.

\begin{tabular}{|c|c|c|c|c|c|}
\hline & \multicolumn{2}{|c|}{$\begin{array}{l}\text { Mass (ng) injected } \\
\text { into the GC-MS }\end{array}$} & \multicolumn{2}{|c|}{$\begin{array}{l}\text { Concentration }\left(\mathrm{pg} \mathrm{m}^{-3}\right) \text { in } \\
\text { atmospheric particulate matter }\end{array}$} & \multirow[b]{2}{*}{ Recovery (\%) } \\
\hline & 2-Me-4-nitrophenol & 4-Me-2-nitrophenol & 2-Me-4-nitrophenol & 4-Me-2-nitrophenol & \\
\hline From $19 / 06$ to $22 / 06 / 07$ & $0.30 \pm 0.06$ & $0.10 \pm 0.03$ & $13.0 \pm 3.2$ & $6.0 \pm 1.8$ & $46 \pm 5$ \\
\hline From $22 / 06$ to $25 / 06 / 07$ & $0.20 \pm 0.04$ & $0.05 \pm 0.01$ & $18.0 \pm 4.5$ & $4.0 \pm 1.2$ & $35 \pm 4$ \\
\hline From $05 / 07$ to $09 / 07 / 07$ & $0.50 \pm 0.10$ & $0.17 \pm 0.04$ & $13.0 \pm 3.2$ & $5.0 \pm 1.5$ & $46 \pm 5$ \\
\hline From $09 / 07$ to $10 / 07 / 07$ & $0.30 \pm 0.06$ & $0.10 \pm 0.03$ & $23.0 \pm 5.7$ & $13.0 \pm 3.9$ & $35 \pm 4$ \\
\hline \multicolumn{6}{|l|}{ Ridgetown } \\
\hline From $20 / 06$ to $23 / 06 / 07$ & $4.30 \pm 0.66$ & $0.80 \pm 0.20$ & $11.0 \pm 2.2$ & $2.0 \pm 0.6$ & $51 \pm 5$ \\
\hline From $05 / 07$ to $08 / 07 / 07$ & $0.60 \pm 0.13$ & $0.40 \pm 0.10$ & $11.0 \pm 2.7$ & $7.0 \pm 2.1$ & $44 \pm 4$ \\
\hline From $08 / 07$ to $10 / 07 / 07$ & $0.50 \pm 0.10$ & $0.40 \pm 0.10$ & $14.0 \pm 3.5$ & $11.0 \pm 3.3$ & $50 \pm 5$ \\
\hline
\end{tabular}

Table 6. Mass (ng) of 2-methyl-4-nitrophenol in $1 \mu$ of the final solution from extraction of filters collected at York University and the corresponding concentrations in the atmosphere.

\begin{tabular}{lccc}
\hline & $\begin{array}{c}\text { Mass (ng) injected } \\
\text { into the GC-MS }\end{array}$ & $\begin{array}{c}\text { Concentration }\left(\mathrm{pg} \mathrm{m}^{-3}\right) \text { in } \\
\text { atmospheric particulate matter }\end{array}$ & \\
\hline York University & 2-Me-4-nitrophenol & 2-Me-4-nitrophenol & Recovery (\%) \\
\hline 2007 & & & \\
\hline From 28/09 to 01/10 & $5.2 \pm 1.0$ & $60 \pm 12$ & $44 \pm 4$ \\
From 04/10 to 07/10 & $7.4 \pm 1.3$ & $140 \pm 23$ & $37 \pm 3$ \\
From 10/10 to $13 / 10$ & $11.5 \pm 2.3$ & $110 \pm 20$ & $43 \pm 4$ \\
\hline 2008 & & & $45 \pm 4$ \\
\hline From 04/07 to 07/07 & $5.2 \pm 1.0$ & $220 \pm 46$ & $48 \pm 5$ \\
From 08/07 to 11/07 & $13.8 \pm 2.8$ & $100 \pm 22$ & $21 \pm 2$ \\
From 11/07 to 14/07 & $5.3 \pm 1.0$ & $202 \pm 40$ & $48 \pm 5$ \\
From 15/07 to $17 / 07$ & $3.7 \pm 0.8$ & $100 \pm 22$ & $42 \pm 4$ \\
From 18/07 to 21/07 & $15.4 \pm 3.1$ & $90 \pm 18$ & $36 \pm 3$ \\
From 25/07 to 28/07 & $3.9 \pm 0.9$ & $190 \pm 38$ & \\
From 25/08 to 28/08 & $6.0 \pm 1.2$ & & \\
\hline
\end{tabular}

final GC-IRMS measurements depends on the quality of the HPLC separation as well as on the width of the collection windows and therefore is strongly dependent on the number of compounds targeted for analysis. In this study the final HPLC clean-up was tuned to be specific for the most abundant methylnitrophenols and the internal standards, minimizing peak overlap in the GC separation, a key condition for accurate isotope ratio measurements by GC-IRMS.
One disadvantage of HPLC sample purification is that the composition of the solvent in which the target substances are dissolved after separation is determined by the conditions of the HPLC separation and not its suitability for GCanalysis. In our application the methylnitrophenols are eluted in an acetonitrile-water mixture with about $50 \%$ water content, which is unsuitable for carrying out a derivatisation with BSTFA and analysis by GC-MS or GC-IRMS. 
Table 7. Stable isotope ratio (\%o) of 2-methyl-4-nitrophenol in ambient particulate matter samples collected at York University.

\begin{tabular}{lccc}
\hline \multicolumn{4}{c}{ 2-Methyl-4-nitrophenol stable isotope ratio (\%o) } \\
\hline York University & 1st measurement & 2nd measurement & Average \\
\hline 2007 & & \\
\hline From 28/09 to 01/10 & $-32.9 \pm 0.5$ & $-32.9 \pm 0.5$ & $-32.9 \pm 0.5$ \\
From 04/10 to 07/10 & $-31.7 \pm 0.5$ & $-31.8 \pm 0.5$ & $-31.8 \pm 0.5$ \\
\hline \multicolumn{4}{c}{} \\
\hline From 04/07 to 07/07 & $-31.6 \pm 0.5$ & $-31.6 \pm 0.5$ & $-31.6 \pm 0.5$ \\
From 18/07 to 21/07 & $-31.8 \pm 0.5$ & $-31.8 \pm 0.5$ & $-31.8 \pm 0.5$ \\
From 25/08 to 28/08 & NA & $-32.1 \pm 0.5$ & $-32.1 \pm 0.5$ \\
\hline
\end{tabular}

* The uncertainties given are estimated uncertainties for the complete analytical procedure.

Changing the solvent composition is the main purpose of the Solid Phase Extraction (SPE) step in the method. In order to achieve a high efficiency for the SPE (Table 3), the organic solvent content of the solution is substantially reduced by evaporating about $50 \%$ of the total volume in a rotary evaporator and its $\mathrm{pH}$ is adjusted to approximately $\mathrm{pH}$ 2 which efficiently suppresses dissociation of phenols. Recovery of methylnitrophenols can be achieved with a variety of solvents. Acetonitrile was chosen for its suitability as a solvent for the derivatisation procedure and its high volatility, which facilitates volume reduction by evaporation as well as splitless GC-injection.

The presented method includes several separation steps combined with volume reduction. Although the loss of sample for each individual step is generally only $20 \%$ or less, the combination of a series of sample processing steps results in a relatively low overall recovery (Tables 2 and 3). Nevertheless, the estimated relative accuracy of concentration measurements is around $20 \%$. This is due to the chemical similarity between target compounds and internal standards, which results in recovery ratios close to unity (Table 2).

One of the main advantages of the somewhat elaborate sample clean-up steps is that the detection limit is primarily determined by the baseline noise of the gas chromatographic measurement. Combined with the possibility to process large samples this results in detection limits significantly lower than those of previously published methods (Morville et al., 2004; Cecinato et al., 2005). The detection limit for this method is $0.3 \mathrm{pg} \mathrm{m}^{-3}$ for 2-methyl-4-nitrophenol and 4methyl-2-nitrophenol. Based on our results and data from literature (Herterich and Herrmann, 1990; Cecinato et al., $2005)$ this is orders of magnitude lower than any concentration expected for suburban and rural areas. The predominantly anthropogenic origin of toluene as well as the available observations strongly suggest that the atmospheric abundance of methylnitrophenols strongly decreases with increasing distance from urban and industrialized areas. The method presented here has the potential to allow methylnitrophenol measurements at truly remote locations.

The method presented here allows compound specific stable carbon isotope ratio measurements in POM for compounds with an identified VOC precursors. Carbon isotope ratios of methylnitrophenols, which are formed by the atmospheric oxidation of toluene, could be analysed at concentrations as low as $0.1 \mathrm{ng} \mathrm{m}^{-3}$ by GC-IRMS with an estimated accuracy of $0.5 \%$ and a reproducibility of $0.1 \%$. Processing of filters spiked with methylnitrophenols of known carbon isotope ratio confirmed that sample processing does not cause detectable carbon isotope fractionation. Furthermore, the isotope ratios of internal standards determined in filter extracts by GC-IRMS are, within the estimated experimental uncertainty, identical to the values determined by off-line isotope ratio measurements. The absence of detectable isotope fractionation strongly suggests that losses during sample processing are primarily due to physical processes and not to chemical reactions.

One of the main limitations of the method is the necessity to collect samples for a few days to accumulate sufficient methylnitrophenol mass on the filter. This reduces the possibilities to determine short-term variability of concentration and also increases the risk of sampling bias. This problem is somewhat specific for areas with low nitrophenol concentration. In several published studies methylnitrophenol concentration were reported, which exceed the levels observed at York University by an order of magnitude or more (Herterich and Herrmann, 1990; Cecinato et al., 2005). For these conditions duration of sampling could be reduced accordingly.

The final goal of measurements of isotope ratios of secondary POM is to better understand precursor processing in the atmosphere and add new constraints for extrapolation of laboratory experiments to atmospheric conditions. The data set presented here is very limited and it would be premature to generalize the findings. Moreover, due to the restriction of isotope ratio measurements to samples with 


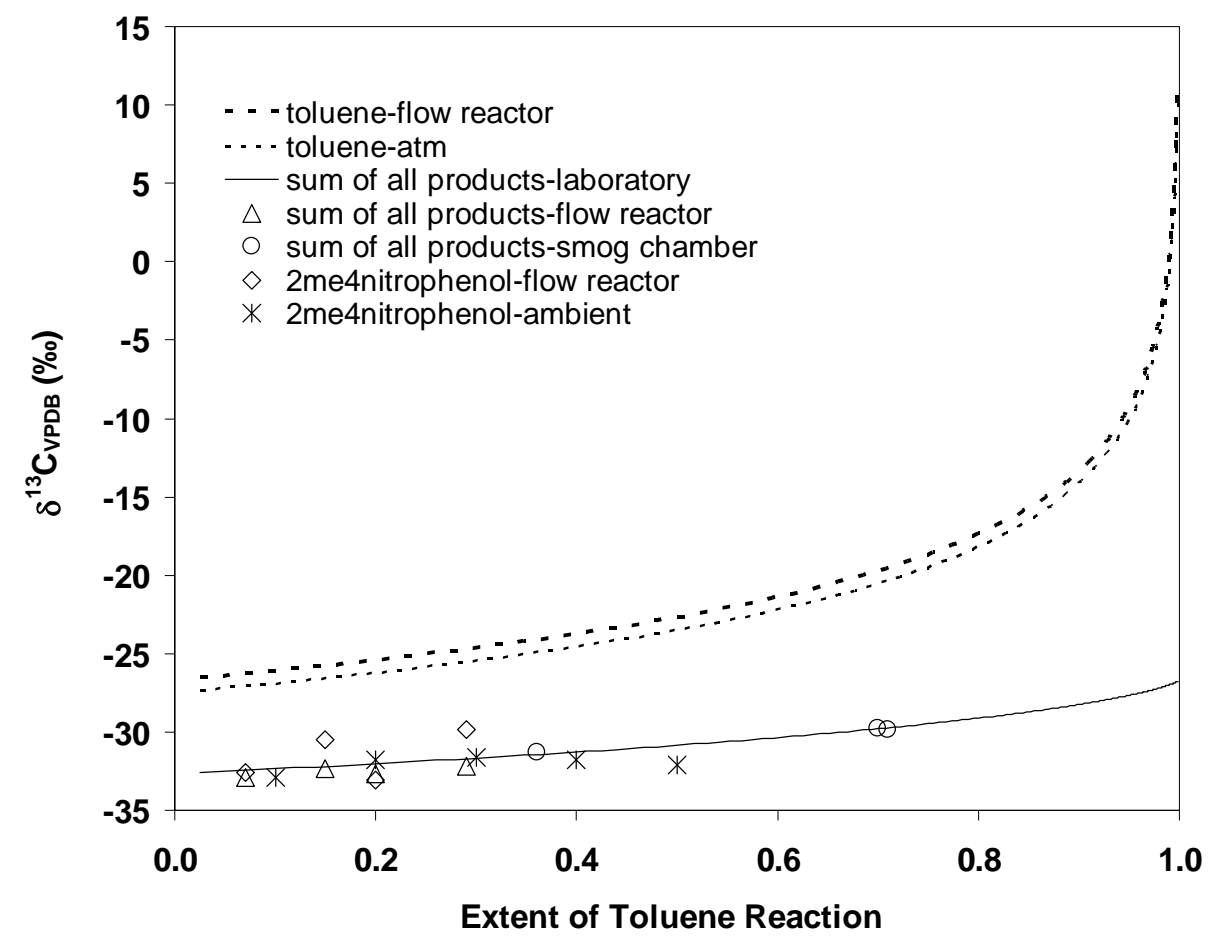

Fig. 4. Stable isotope ratio of toluene and its products as function of toluene processing. The broken lines are calculations based on the initial isotope ratio of toluene. The solid line is the isotope ratio of POM formed by the oxidation of toluene calculated from mass balance under the assumption that there is no fractionation between the phases. Individual data points represent measurements of the carbon isotope ratio of total POM. The flow reactor and smog chamber data are taken from Irei et al. (2006, 2011) and Irei (2008). It should be noted that the position of the ambient 2-methyl-4-nitrophenol data along the x-axis does not indicate the extent of toluene processing. Spreading out the data is done for the purpose of indicating the extent of variability as well as to show that these data are consistent with laboratory observations up to at least $30 \%$ of toluene processing.

methylnitrophenol concentrations at the upper end of observed ambient levels, our findings do not necessarily apply to conditions with methylnitrophenol levels at the lower end of the observed concentration range.

Nevertheless, our results allow some important progress in understanding the origin of atmospheric methylnitrophenols in particulate matter, with the caveat that they may not be representative for the atmosphere in general. First of all, the carbon isotope ratio of 2-methyl-4-nitrophenol in samples collected at York University is in the relatively narrow range of $-31.6 \%$ to $-32.9 \%$ with an average of $-32.0 \%$ $\pm 0.2 \%$ (standard deviation $0.5 \%$ ). This is significantly lighter than toluene stable isotope ratios measured close to major sources (Rudolph et al., 2002). This study included toluene sources in Toronto and its surrounding suburbs. Therefore the reported values, which range from $(-28.4 \pm 2.9 \%$ o to $(-27.1 \pm 0.7 \%$ ) , provide a solid basis for comparison with toluene oxidation products at York University. Based on our measurements 2-Methyl-4-nitrophenol in particulate matter is depleted in ${ }^{13} \mathrm{C}$ by $4 \% 0-5 \%$ compared to the toluene precursor. This is consistent with the known kinetic isotope effect for the reaction of toluene with $\mathrm{OH}$ of $(5.95 \pm 0.28 \%$ ) (Anderson et al., 2004). Based on the ki- netic isotope effect and mass budget considerations the products of toluene oxidation in the initial phase of the reaction will be 5\%o-6\%o lighter than the parent compound. Indeed, Irei et al. (2006) observed that secondary POM formed by the OH-radical initiated oxidation of toluene in a flow reactor is on average $5.6 \%$ lighter under conditions where less than $30 \%$ of toluene has reacted (Fig. 4). Furthermore, Irei (2008) reports measurements of the isotope ratios of 2methyl-4-nitrophenol formed by the oxidation of toluene in a smog chamber and in a flow reactor. The observed isotope ratio was on average $(4 \pm 1 \%$ ) lighter than that of the reactant. This is in very good agreement with our ambient observations and supports the hypothesis that 2-methyl4-nitrophenol found in atmospheric particulate matter is the product of the atmospheric oxidation of toluene. Furthermore, the similarity of predicted and observed isotope ratios is evidence that reaction mechanisms in the laboratory and in the atmosphere are similar, although the yields are very different (see below). Based on mass balance considerations as well as results from laboratory studies it is expected that the stable isotope ratio of the products of toluene oxidation depends on the extent of precursor processing (Fig. 4). Within the uncertainty and scatter of the measurements the ambient 
data agree very well with the laboratory studies for less than $30 \%$ of toluene processing. This is consistent with the average atmospheric lifetime of toluene (approximately 2 days) and a sampling location in a suburban area of a major city.

It should be noted that the extremely low concentrations of 2-methyl-4-nitrophenol in atmospheric particulate matter suggest that the particulate phase methylnitrophenol yield under atmospheric conditions is substantially lower than in laboratory studies (Irei, 2008). This may be explained by differences in phase distributions resulting from the lower particulate matter load in the atmosphere or an unrealistically high methylnitrophenol yield in laboratory studies due to the very high $\mathrm{NO}_{\mathrm{x}}$ concentrations used in laboratory studies (Irei, 2008).

Semi-volatile compound sampling on high-volume filters carries the risk of losses during sampling due to volatilisation of semi-volatile compounds from collected particles, which would result in measurements underestimating atmospheric concentrations. In contrast to this, adsorption of gas-phase methylnitrophenols on quartz fibres potentially results in an overestimation of particle-phase concentrations. It is difficult to estimate the extent of such bias and therefore it is not possible to provide an uncertainty estimate arising from these effects for concentration measurements. However, it is unlikely that isotope ratio measurements will be significantly biased by volatilisation or adsorption. Phase transitions such as evaporation typically only cause very small isotope effects. For example Irei et al. (2006) found a difference of $(0.33 \pm 0.02 \%$ ) between gas and liquid phase during partial evaporation of toluene. It therefore is very likely that for isotope ratio measurements the bias from changes in distribution between particle-phase and gas-phase during sampling will be below the estimated overall uncertainty of the isotope ratio measurements of $0.5 \%$.

\section{Conclusions}

The developed method for compound specific analysis of methylnitrophenols in atmospheric particulate matter allows measurements with an accuracy of $0.5 \%$ or concentrations in the range of $0.1 \mathrm{ng} \mathrm{m}^{-3}$. This is sufficient for studies of the methylnitrophenol isomer most abundant in atmospheric particulate matter in a suburban region, but not over rural and semi-rural regions. Processing filter extracts by a combination of several volume reduction and an HPLC sample clean-up step with GC-IRMS measurements allows complete chromatographic peak separation, a condition for unbiased compound specific isotope ratio measurement. While the method was only tested for analysis of methylnitrophenols, the flexibility of HPLC separation combined with the wide range of compounds that can be analysed by GC makes it a method that can readily be adapted to many components of atmospheric POM.
One of the by-products of this method development is the possibility to measure methylnitrophenol concentrations in atmospheric particulate matter at the lowest $\mathrm{pg} \mathrm{m}^{-3}$ range, which is most likely sufficient for concentration measurements over rural and remote locations.

The carbon isotope ratio of 2-methyl-4-nitrophenol is 4$5 \%$ lower than that of the toluene precursor. This is consistent with laboratory studies of the products of toluene oxidation as well as mass balance based predictions. This strongly suggests that the most abundant atmospheric methylnitrophenol, 2-methyl-4-nitrophenol, is primarily to the result of atmospheric oxidation of toluene and that the formation mechanism in the atmosphere is very similar to that in laboratory studies, although yields substantially differ. Due to the limited number of isotope ratio measurements it is uncertain to which extent these findings can be generalized, but the results presented here demonstrate the value of isotope ratio measurements for understanding the origin and formation processes of organic atmospheric pollutants.

Acknowledgements. This study was supported by the Canadian Foundation for Climate and Atmospheric Sciences, and the Natural Sciences and Engineering Research Council of Canada.

Edited by: D. Griffith

\section{References}

Anderson, T. L., Charlson, R. J., Schwartz, S. E., Knutti, R., Boucher, O., Rodhe, H., and Heintzenberg, J.: Climate forcing by aerosols - A hazy picture, Science, 300, 1103-1104, 2003.

Anderson, R. S., Iannone, R., Thompson, A. E., Rudolph, J., and Huang, L.: Carbon kinetic isotope effects in the gas-phase reactions of aromatic hydrocarbons with the $\mathrm{OH}$ radical at $296 \pm 4 \mathrm{~K}$, Geophys. Res. Lett., 31, L15108, doi:10.1029/2004GL020089, 2004.

Blanchard, P., Brook, J. R., and Brazal, P.: Chemical characterization of the organic fraction of atmospheric aerosol at two sites in Ontario, Canada, J. Geophys. Res. Atmos., 107, ICC10/1ICC10/8, 2002.

Cecinato, A., Vincenzo, D. P., Pomata, D., Tomasi Sciano, M. C., and Possanzini, M.: Measurement of phase-distributed nitrophenols in Rome ambient air, Chemosphere, 59, 679-683, 2005.

Craig, H.: Isotopic standards for carbon and oxygen and correction factors for mass-spectroscopic analysis of carbon dioxide, Geochem. Cosmo. Acta, 12, 133-149, 1957.

Fisseha, R., Spahn, H., Wegener, R., Hohaus, T., Brasse, G., Wissel, H., Tillmann, R., Wahner, A., Koppmann, R., and KiendlerScharr, A.: Stable carbon isotope composition of secondary organic aerosol from $\beta$-pinene oxidation, J. Geophys. Res., 114, D020304, doi:10.1029/2008JD011326, 2009.

Forstner, H. J. L., Flagan, R. C., and Seinfeld, J. H.: Secondary organic aerosol from the photooxidation of aromatic hydrocarbons: Molecular composition, Environ. Sci. Technol., 31, 1345-1358, 1997. 
Goldstein, A. H. and Shaw, S. L.: Isotopes of volatile organic compounds: An emerging approach for studying atmospheric budgets and chemistry, Chem. Rev., 103, 5025-5048, 2003.

Hamilton, J. F., Webb, P. J., Lewis, A. C., and Reviejo, M. M.: Quantifying small molecules in secondary organic aerosol formed during the photo-oxidation of toluene with hydroxyl radicals, Atmos. Environ., 39, 7263-7275, 2005.

Harper, D. B., Hamilton, J. T., Ducrocq, V., Kennedy, J. T., Downey, A., and Kalin, R. M.: The distinctive isotopic signature of plantderived chloromethane: Possible application in constraining the atmospheric chloromethane budget, Chemosphere, 52, 433-436, doi:10.1016/s0045-6535(03)00206-6, 2003.

Herterich, R. and Herrman, R.: Comparing the distribution of nitrated phenols in the atmosphere of two German hill sites, Environ. Technol., 11, 961-972, 1990.

Huang, L., Sturcio, N. C., Abrajano, T. Jr., Heraty, J., and Holt, B. D.: Carbon and chlorine isotope fractionation of chlorinated aliphatic hydrocarbons by evaporation, Org. Geochem., 30, 777785, 1999.

Iannone, R., Koppmann, R., and Rudolph, J.: Stable carbon kinetic isotope effects for the production of methacrolein and methyl vinyl ketone from the gas-phase reactions of isoprene with ozone and hydroxyl radicals, Atmos. Environ., 44, 4135-4141, 2010.

Irei, S.: Laboratories studies of stable carbon isotope ratio of secondary particulate organic matter in the gas phase, Ph.D. Dissertation, York University, 2008.

Irei, S., Huang, L., Collin, F., Zhang, W., Hastie, D., and Rudolph, J.: Flow reactor studies of the stable carbon isotope composition of secondary particulate organic matter generated by $\mathrm{OH}$-radicalinduced reactions of toluene, Atmos. Environ., 40, 5858-5867, 2006.

Irei, S., Rudolph, J., Huang, L., Auld, J., and Hastie, D.: Stable carbon isotope ratio of secondary particulate organic matter formed by photooxidation of toluene in indoor smog chamber, Atmos. Environ., 45, 856-862, 2011.

Jang, M. and Kamens, R. M.: Characterization of secondary aerosol from the photooxidation of toluene in the presence of $\mathrm{NO}_{\mathrm{x}}$ and 1-propene, Environ. Sci. Technol., 35, 3626-3639, 2001.

Li, L., Deng, S., Wang, W., Li, H., Zhang, X., Sheng, G., Fu, J., Bi, X., and Sun, B.: Determination of the stable carbon isotopic compositions of 2-methyltetrols in ambient aerosols from the Changbai Mountains, Rapid Communications in Mass Spectrometry, 24, 1625-1628, 2010.

Matthews, D. E. and Hayes, J. M.: Isotope-ratio-monitoring gas chromatography-mass spectrometry, Anal. Chem., 50, 14651473, 1978.

Morville, S., Scheyer, A., Mirabel, P., and Millet, M.: A multiresidue method for the analysis of phenols and nitrophenols in the atmosphere, J. Environ. Monit., 6, 963-966, 2004.
Pandis, S. N., Harley, R. A., Cass, G. R., and Seinfeld, J. H.: Secondary organic aerosol formation and transport, Atmos. Environ., 26A, 2269-2282, 1992.

Ramanathan, V., Crutzen, P. J., Kielh, J. T., and Rosenfeld, D.: Aerosols, climate, and the hydrological cycle, Science, 294, 2119-2124, 2001.

Redeker, K. R., Davis, S., and Kalin, R. M.: Isotope values of atmospheric halocarbons and hydrocarbons from Irish urban, rural, and marine locations, J. Geophys. Res., 112, D16307, doi:10.1029/2006jd007784, 2007.

Rudolph J., Lowe, D. C., Martin, R. J., and Clarkson, T. S.: A novel method for the compound specific determination of $\delta^{13} \mathrm{C}$ in volatile organic compounds at ppt levels in ambient air, Geophys. Res. Lett., 24, 659-662, 1997.

Rudolph, J. and Czuba, E.: On the use of isotopic composition measurements of volatile organic compounds to determine the "photochemical age" of an air mass, Geophys. Res. Lett., 27, 38653868, 2000.

Rudolph, J. and Stupak, J.: Determination of aromatic acids and nitrophenols in atmospheric aerosols by capillary electrophoresis, J. Chromtogr. Sci., 40, 207-213, 2002.

Rudolph, J., Czuba, E., Norman, A. L., Huang, L., and Ernst, D.: Stable carbon composition of nonmethane hydrocarbons in emissions from transportation related sources and atmospheric observations in an urban atmosphere, Atmos. Environ., 36, 11731181, 2002.

Rudolph, J.: Gas chromatography-isotope ratio mass spectrometry, in: Volatile Organic Compounds in the Atmosphere, edited by: Koppmann, R., Blackwell Publishing, ISBN 9781405131155, 2007.

Thompson, A. E., Anderson, R. S., Rudolph, J., and Huang, L.: Stable carbon isotope signatures of background tropospheric chloromethane and CFC113, Biogeochemistry, 60, 191-211, 2002.

Thurston, G. D., Ito, K., Hayes, C. G., Bates, D. V., and Lippmann, M.: Respiratory hospitals admissions and summertime haze air pollution in Toronto, Ontario: Consideration of the role of acid aerosols, Environ. Res., 65, 271-290, 1994.

Tsigaridis, K. and Kanakidou, M.: Global modelling of secondary organic aerosol in the troposphere: A sensitivity analysis, Atmos. Chem. Phys., 3, 1849-1869, doi:10.5194/acp-3-1849-2003, 2003.

Tsunogai, U., Yoshida, N., and Gamo, T.: Carbon isotopic compositions of $\mathrm{C}_{2}-\mathrm{C}_{5}$ hydrocarbons and methyl chloride in urban, coastal, and maritime atmospheres over the western North Pacific, J. Geophys. Res., 104, 16033-16039, doi:10.1029/1999jd900217, 1999.

Turpin, B. J., Saxena, P., and Andrews, E.: Measuring and simulating particulate organics in the atmosphere - problems and prospects, Atmos. Environ., 34, 2983-3013, 2000. 